\title{
The influence of dietary supplementation with the leucine metabolite $\beta$-hydroxy- $\beta$-methylbutyrate (HMB) on the chemotaxis, phagocytosis and respiratory burst of peripheral blood granulocytes and monocytes in calves
}

Roman Wójcik ( $\square$ brandy@uwm.edu.pl )

University of Warmia and Mazury in Olsztyn https://orcid.org/0000-0002-7405-6328

Joanna Małaczewska

Uniwersytet Warminsko-Mazurski Wydzial Medycyny Weterynaryjnej

Grzegorz Zwierzchowski

Uniwersytet Warminsko-Mazurski Wydzial Biologii i Biotechnologii

Jan Miciński

Uniwersytet Warminsko-Mazurski Wydzial Bioinżynierii Żwierząt

Edyta KaczorekŁukowska

Uniwersytet Warminsko-Mazurski Wydzial Medycyny Weterynaryjnej

Research article

Keywords: $\beta$-hydroxy- $\beta$-methylbutyrate, granulocytes, monocytes, chemotaxis, phagocytosis, respiratory burst calves

Posted Date: June 29th, 2020

DOI: https://doi.org/10.21203/rs.2.20386/v6

License: (c) (1) This work is licensed under a Creative Commons Attribution 4.0 International License. Read Full License

Version of Record: A version of this preprint was published at BMC Veterinary Research on June 1st, 2020. See the published version at https://doi.org/10.1186/s12917-020-02389-1. 


\section{Abstract}

Background A healthy immune system plays a particularly important role in newborns, including in calves that are far more susceptible to infections (viral, bacterial and other) than adult individuals. Therefore, the present study aimed to evaluate the influence of HMB on the chemotactic activity (MIGRATEST® kit), phagocytic activity (PHAGOTEST ${ }^{\circledR}$ kit) and oxidative burst (BURSTTEST ${ }^{\circledR}$ kit) of monocytes and granulocytes in the peripheral blood of calves by flow cytometry.

Results An analysis of granulocyte and monocyte chemotactic activity and phagocytic activity revealed significantly higher levels of phagocytic activity in calves administered HMB than in the control group, expressed in terms of the percentage of phagocytising cells and mean fluorescence intensity (MFI). HMB also had a positive effect on the oxidative metabolism of monocytes and granulocytes stimulated with PMA (4-phorbol-12- $\beta$-myristate-13-acetate) and Escherichia coli bacteria, expressed as MFI values and the percentage of oxidative metabolism.

Conclusion HMB stimulates non-specific cell-mediated immunity, which is a very important consideration in newborn calves that are exposed to adverse environmental factors in the first weeks of their life. The supplementation of animal diets with HMB for both preventive and therapeutic purposes can also reduce the use of antibiotics in animal production.

\section{Background}

Considerable research has been done into preparations that simulate immune mechanisms, in particular non-specific cell-mediated and humoral immunity, in the youngest animals $[1,2,3,4,5]$. A healthy immune system plays a particularly important role in newborns, including in calves that are far more susceptible to infections (viral, bacterial and other) than adult individuals $[6,7,8]$.

Non-infectious factors, such as the season of birth, low birth weight, unfavorable environment, absence of colostrum feeding after birth or colostrum feeding at an inappropriate time, as well as infectious factors that cause gastrointestinal and respiratory diseases, are the most frequent causes of disease that contribute to high mortality in newborn calves and cause production losses $[6,7,8,9,10,11,12,13,14,15]$. These diseases are difficult to treat and the prognosis is doubtful, which is why prevention, including immunoprevention, could play a very important role in calf rearing $[16,17,18]$. The search for effective immunostimulants, in particular feed additives, continues, and $\beta$-hydroxy- $\beta$-methylbutyrate (HMB) could be one of such supplements.

Beta-hydroxy- $\beta$-methylbutyrate occurs naturally in humans, animals and plants. This endogenous metabolite of the branched-chain amino acid (BCAA) leucine (LEU) is produced when leucine is oxidised in the cell cytoplasm, mainly in the liver and muscles. Nearly $80 \%$ of endogenous LEU is used in protein synthesis, and the remainder is transformed into a-ketoisocaproate (a-KIC) which can undergo further conversion in two processes. The first process occurs in the mitochondria where a-KIC is oxidised to isovaleryl-CoA by branched-chain ketoacid dehydrogenase (BCKAD). 3-hydroxy-3-methylglutaryl- 
coenzyme A (HMG-CoA) is synthesised after several steps. An alternative process takes place in the cytosol where HMB is produced from a-KIC by the KIC dioxygenase enzyme. Under normal conditions, approximately $5 \%$ of leucine is metabolised into $\mathrm{HMB}$, whereas $\mathrm{KIC}$ is mostly converted to isovaleryl-CoA $[19,20]$.

Small quantities of HMB are found in alfalfa, corn (corn silage), milk, cheese, citrus fruit (grapefruit), selected fish species (catfish), red wine and red meat. The quantity of HMB that occurs naturally in the body and is supplied with food is insufficient and, therefore, has to be supplemented from external sources $[21,22,23]$. HMB is a safe compound that does not produce side effects even if administered at excessive doses, and excess HMB is excreted with urine [24].

According to research studies conducted on several animal species: pigs [25,26,27], cattle [28,29], goats [30], chickens [31], geese [32] and fish [33,34] HMB can stimulate immune mechanisms. However, little is known about its exact mechanism of action and effects on different immunity parameters in animals, including calves. Therefore, the aim of this study was to evaluate the effect of dietary supplementation with $\mathrm{HMB}$ on the chemotaxis, phagocytosis and respiratory burst of peripheral blood granulocytes and monocytes in calves. The present study complements our previous research into the influence of HMB on selected parameters of non-specific cell-mediated [28] and humoral immunity [29] in calves.

\section{Results}

The chemotactic activity of peripheral blood neutrophils in calves was expressed by the chemotactic index (Figure 1A, Figure 1B). On experimental days 30 and 60, the mean values of the chemotactic index increased significantly ( $p<0.001$ and $p<0.01$, respectively) in the group of calves whose diets were supplemented with HMB (experimental group) in comparison with the non-supplemented animals (control group). In the experimental group, the mean value of the chemotactic index also increased significantly $(p<0.001)$ on experimental days 30 and 60 relative to its mean baseline value (day 0$)$.

The analysis of the phagocytic activity of peripheral blood neutrophils revealed that the mean percentage of phagocytising neutrophils was significantly higher $(\mathrm{p}<0.05$ or $\mathrm{p}<0.01)$ (Figure 2A, Figure $2 \mathrm{~B})$ in the experimental group than in the control group throughout the entire experiment. In the experimental group, the mean percentage of phagocytising neutrophils increased significantly $(p<0.05)$ on days 30 and 60 relative to the mean baseline value of this parameter on day 0 . The MFI of granulocytes, which denotes the number of bacteria ingested per phagocyte (Figure 2C), increased significantly $(p<0.001, p<0.01$ respectively) between experimental days 15 and 30 in the experimental group relative to the control group and relative to the mean baseline value (day 0 ).

The phagocytic activity of peripheral blood monocytes, expressed as the mean percentage of phagocytising monocytes (Figure 3A, Figure 3B), on experimental days 30 and 60 increased significantly $(p<0.0001, p<0.001$ respectively) in the experimental group relative to the control group and relative to the mean baseline value (day 0 ). Similarly to neutrophils, the MFI of monocytes, which denotes the number of bacteria ingested per phagocyte (Figure 3C), increased significantly $(p<0.0001, p<0.001$ 
respectively) between experimental days 15 and 30 in the experimental group relative to the control group and relative to the mean baseline value (day 0 ).

The respiratory burst activity (metabolism of highly reactive oxygen species) of peripheral blood neutrophils increased in the experimental group fed HMB-supplemented diets relative to the control group and relative to the mean baseline value (day 0 ) throughout the entire experiment. An increase was observed in the mean percentage of cells stimulated to undergo respiratory burst (Figure 4A, Figure 4B) and in the MFI of neutrophils denoting the respiratory burst activity of different neutrophils (Figure 4C). However, a significant $(p<0.05$ or $p<0.01$ or $p<0.001$ or $p<0.0001)$ increase in the mean values of the above parameters was observed only after stimulation with potent respiratory burst activators, PMA and E. coli bacteria, throughout the entire experiment. The stimulation with $\mathrm{N}$-formyl-methionyl-leucylphenylalanine (fMLP), a weak activator of respiratory burst, did not induce significant differences in the mean percentage of cells stimulated to undergo respiratory burst or the MFI of neutrophils between the control group and the experimental group or relative to the mean baseline values (day 0) (Figure 4A).

Similarly to granulocytes, the stimulation of peripheral blood monocytes with E. coli, PMA and fMLP significantly $(p<0.05$ or $p<0.01$ or $p<0.001)$ increased the mean percentage of cells stimulated to undergo respiratory burst (Figure $5 \mathrm{~A}$, Figure $5 \mathrm{~B}$ ) and the mean intensity of respiratory burst in monocytes (Figure $5 \mathrm{C}$ ) in the experimental group relative to the control group and relative to mean baseline values (day 0).

\section{Discussion}

This study evaluated the effect of the supplementation of calf diets with HMB, a natural metabolite of leucine, on different stages of phagocytosis: chemotaxis and intracellular ingestion and killing of bacteria by peripheral blood granulocytes and monocytes.

There is considerable evidence to indicate that HMB stimulates non-specific immune mechanisms, including phagocytosis, in many animal species: pigs [35], chicken [31,36], geese [32] and fish [34,37,38] however, these effects have been rarely investigated in calves [28]. HMB is a strong anticatabolic agent and a regulator of protein metabolism, and it is widely used in sports and bodybuilding to increase strength, muscle mass and exercise performance $[39,40,41,42,43]$. Immune health is also highly correlated with protein synthesis because mounting immune responses require the generation of new cells and the synthesis of antigen-presenting machinery, immunoglobulins, cytokines, cytokine receptors and acute phase proteins.

In the present study, the observed increase in the chemotactic activity of peripheral blood neutrophils, expressed as the chemotactic index as the most accurate parameter for assessing chemotactic activity [44], in the group of experimental calves supplemented with HMB relative to control group calves cannot be compared with published data because such experiments have not been conducted in calves or in other animal species. As mentioned previously, numerous authors $[28,31,32,34,35,36,37,38]$ have reported on the positive effects of HMB on phagocytosis in several animal species, but the supplement's impact 
on specific stages of phagocytosis has never been described. Of note, unlike in humans, typical fMLP receptors are not expressed on the surface of WBC in cattle, and this fact has never been disputed in the article. However, certain doubts remain, and they appear to be backed by the literature. The theory that typical fMLP receptors are not expressed on the surface of bovine WBC was postulated in the last century, and the research conducted in the past decade has provided evidence to the contrary. These findings could be insignificant, but I think they are worth mentioning. The responses of bovine granulocytes to the FMLP chemoattractant in the MIGRATEST ${ }^{\circledR}$ suggest that these cells are bound to a receptor. However, this receptor has not been identified, and it is possible that other receptors on the surface of bovine WBC play the role of typical fMLP receptors or that co-receptors are involved. These are merely speculations because these receptors have not been identified.

The significant increase in the phagocytic activity of monocytes and granulocytes in the experimental group relative to the control group was reflected by an increase in the percentage of phagocytising cells as well as an increase in the mean number of bacteria ingested per phagocyte, expressed as MFI. Similar results were noted in our previous studies of geese [32] and goats [45]. In a study by Siwicki et al. [37], the potential killing activity (PKA) of granulocytes and monocytes increased by $140 \%$ in fish (rainbow trout and carp) stimulated with various doses of HMB relative to the control group. The analysed supplement exerted the most stimulatory effect on PKA when administered at doses higher than $50 \mathrm{mg} \mathrm{HMB} / \mathrm{mL}$. A study of rainbow trout [38] fed pellets with various $\operatorname{HMB}$ content $(0,10,25$ or $50 \mathrm{mg} / \mathrm{kg} \mathrm{BW} /$ day) for 8 weeks confirmed that HMB stimulates the activity of phagocytes ( $100 \%$ increase in PKA) relative to the control group. Similar results were reported by Siwicki et al. [46] who examined the effect of two HMB doses (50 and $100 \mathrm{mg} \mathrm{HMB} / \mathrm{kg} \mathrm{BW/day)} \mathrm{administered} \mathrm{over} \mathrm{a} \mathrm{period} \mathrm{of} 4$ weeks on non-specific cellmediated immunity in the common carp (Cyprinus carpio). The PKA of pronephric phagocytes was significantly higher $(p<0.05)$ in HMB-fed carp than in the control group. However, significant differences were not observed between experimental carp administered HMB doses of 50 and $100 \mathrm{mg} / \mathrm{kg} \mathrm{BW} /$ day.

In the current study, HMB also significantly enhanced the intracellular killing activity of granulocytes and monocytes stimulated with strong mitogens (PMA and E. coli bacteria), which was expressed by an increase in the percentage of cells stimulated to undergo respiratory burst and in MFI in these cells. Higher values of the above parameters indicate that pathogens were more effectively eliminated from the body by phagocytising cells. Similar results were reported by Siwicki et al. [38], where a spectrophotometric analysis in the respiratory burst activity test revealed that the production of highly reactive oxygen species by head kidney phagocytes doubled in rainbow trout whose diets were supplemented with HMB for 8 weeks. In a study of rainbow trout (Oncorhynchus mykiss) and carp (Cyprinus carpio) [40], the addition of $>50 \mathrm{mg} / \mathrm{ml} \mathrm{HMB}$ to the culture medium increased respiratory burst activity by up to $84 \%(\mathrm{p}<0.01)$ in pronephric phagocytes grown in a culture medium (RPMI-1640) containing $0,0.1,1,5,10,25,50$ or $100 \mathrm{mg} \mathrm{HMB} / \mathrm{mL}$ relative to the cells cultured without HMB. In an in vitro study, Peterson et al. [36] evaluated macrophages that were isolated from a chicken macrophage cell line (MQ-NCSU) and cultured in the presence of 20, 40 and $80 \mu \mathrm{g}$ of HMB. Supernatant fractions were also tested for the presence of nitrite. The phagocytic potential of MQ-NCSU macrophages exposed to 40 
$\mu \mathrm{g}$ of HMB was significantly higher $(31.7 \%)$ relative to the controls. Sephadex-elicited macrophages treated with $80 \mu \mathrm{g} \mathrm{HMB}$ exhibited a $14.4 \%$ increase in phagocytosis compared with controls.

The mechanism by which HMB influences phagocytising cells and other immunocompetent cells, isolated in this experiment, has not yet been fully elucidated. It can be hypothesised that as a leucine catabolite, HMB is an abundant source of energy for biological activities [19] or that it is an effector of energy metabolism.

The results of this study suggest that HMB is a highly effective dietary supplement that stimulates immunity animals. HMB stimulates non-specific cell-mediated immunity, which is a very important consideration in newborn calves that are exposed to adverse environmental factors in the first weeks of their life. The supplementation of animal diets with HMB for both preventive and therapeutic purposes can also reduce the use of antibiotics in animal production.

Although we are aware that number of animals enrolled in presented study might be the limitation, we would like to emphasize that the study was not conducted in a large research centre, but in an academic unit with a limited budget; therefore, all experimental materials had to be managed rationally. Cytometry tests were a considerable financial burden, even for such a small number of animals. We hope to conduct similar research in the future on a larger number animals and with a higher number of the evaluated parameters because the presented topic seems to be highly interesting.

\section{Conclusions}

The results of this study indicate that experimental calves fed diets supplemented with HMB, compared with non-supplemented (control) animals, were characterized by significantly higher levels of granulocyte chemotactic activity (cf. the chemotactic index) and phagocytic activity (cf. the percentage of phagocytes), a significantly higher mean number of ingested bacteria per phagocyte (cf. the mean fluorescence intensity of monocytes and granulocytes), and significantly higher levels of intracellular killing activity of monocytes and granulocytes after stimulation with PMA and $E$. coli (cf. the percentage of stimulated cells and mean fluorescence intensity).

\section{Methods}

\section{Experimental design}

The experiment was performed on 14 Polish Holstein-Friesian calves originating from a private dairy herd located in the north-eastern region of Poland. We are aware that the studied population was rather small; however, the evaluated animals are large, and the number of animals per group fully meets the criteria for conducting research of the type. The calves (aged 30 \pm 2 days) were fed colostrum within 1 hour after birth. Colostrum was administered in the amount of $2 \mathrm{~kg} /$ animal/day for 5 days. After that period, the animals were fed milk replacers until the age of 8 weeks. Immediately after birth, the calves were moved to wooden sheds outside the cow barn. At the age of one month, calves were included in a 60-day study. 
Prior to the experiment, the animals were weighed and subsequently blindly allocated into two groups by the analogue method. The control group (I) comprised calves fed a standard farm-made diet. Between the age of 5 days to 8 weeks, they were fed the Mlekowit (Polmass, Bydgoszcz, Poland) milk replacer in the amount of $4 \mathrm{~L} /$ day/animal in two portions. In the experimental group (II), the same quantity of the milk replacer was supplemented with $\beta$-hydroxy- $\beta$-methylbutyrate (HMB, Metabolic Technologies Inc. Ames, IA, USA) at $40 \mathrm{mg} / \mathrm{kg} \mathrm{BW}$. Beginning from the first week, the animals had unlimited access to solid feed (maize silage, meadow hay and Jösera Kälberkost prestarer) which was supplied in increasing quantities. Fresh water was supplied ad libitum. All calves enrolled in to the study survived the experimental period and were still breed in the herd.

Sample collection

Blood was sampled from the jugular vein prior to HMB supplementation of feed and on days 15, 30 and 60 of the experiment to determine and compare: chemotactic activity (MIGRATEST ${ }^{\circledR}$ kit) (Glycotope Biotechnology $\mathrm{GmbH}$, Heidelberg, Germany), phagocytic activity (PHAGOTEST ${ }^{\circledR}$ kit) (Orpegen Pharma, Heidelberg, Germany) and respiratory burst (BURSTTEST ${ }^{\circledR}$ kit) (Orpegen Pharma, Heidelberg, Germany) of peripheral blood granulocytes and monocytes by flow cytometry.

Determination of the chemotactic activity of blood granulocytes and monocytes in calves with the MIGRATEST ${ }^{\circledR}$ kit

The chemotactic activity of blood granulocytes and monocytes was determined with the MIGRATEST ${ }^{\circledR}$ kit (Orpegen Pharma, Heidelberg, Germany) based on the attached instructions. The assay involved leucocyte-rich plasma (LRP) that was isolated from heparinised whole blood by spontaneous sedimentation. The LRP was extracted from each sample, and it was transferred to two cell culture inserts with pore size of $3.0 \mu \mathrm{M}$. One insert was placed in a well containing $\mathrm{N}$-formyl-methionyl-leucylphenylalanine (fMLP) (Glycotope Biotechnology GmbH, Heidelberg, Germany) as the chemoattractant. The other insert was used as negative control, and it was placed in a buffer solution that did not contain the chemotactic peptide. Chemotaxis was quantified over a period of $30 \mathrm{~min}$ at a temperature of $37^{\circ} \mathrm{C}$. An antibody reagent (FITC-labelled anti-CD62L (Glycotope Biotechnology $\mathrm{GmbH}$, Heidelberg, Germany) containing counting beads was applied for 10 minutes to stain the cells. The samples were placed on ice, and vital DNA dye (Glycotope Biotechnology $\mathrm{GmbH}$, Heidelberg, Germany) was added for 5 min before flow cytometry. The number of migrated neutrophils and L-selectin shedding from the surface of activated cells were determined by flow cytometry. The results were expressed by the chemotactic index which was calculated by dividing the number of cells migrating towards fMLP by the number of migrating cells in the absence of fMLP [47].

Determination of the phagocytic activity of blood granulocytes and monocytes in calves with the PHAGOTEST ${ }^{\circledR}$ kit

The phagocytic activity of blood granulocytes and monocytes was evaluated with the use of the PHAGOTEST ${ }^{\circledR}$ kit (Orpegen Pharma, Heidelberg, Germany) in line with the attached instructions. The 
manufacturer's specifications were also observed in the process of preparing the reagents. The negative control was a $5 \mathrm{~mL}$ test tube (blue, Beckman Coulter, Fullerton, CA, USA) filled with $100 \mu \mathrm{L}$ of whole heparinised blood chilled to $0^{\circ} \mathrm{C}$. The experimental test tube $(5 \mathrm{~mL}$, blue, Beckman Coulter, Fullerton, CA, USA) contained $20 \mu \mathrm{L}$ of chilled E. coli bacteria (Orpegen Pharma, Heidelberg, Germany). Both tubes were shaken at low speed for around 3 seconds. The experimental test tube was incubated at $37^{\circ} \mathrm{C}$ for 10 minutes. The negative control was incubated at $0^{\circ} \mathrm{C}$ on ice. The incubated samples were combined with $100 \mu \mathrm{L}$ of the quenching solution (Orpegen Pharma, Heidelberg, Germany), and the test tubes were shaken. The washing solution (Orpegen Pharma, Heidelberg, Germany) chilled to $0^{\circ} \mathrm{C}$ was added in the amount of $3 \mathrm{ml}$. Both samples were centrifuged for $5 \mathrm{~min}$ at $4^{\circ} \mathrm{C}(250 \mathrm{xg})$, and the supernatant was removed. The samples were rinsed twice, after which, $2 \mathrm{ml}$ of the lysing solution (Orpegen Pharma, Heidelberg, Germany) with room temperature was added to each sample. The samples were shaken, incubated at room temperature for $20 \mathrm{~min}$, and centrifuged for $5 \mathrm{~min}$ at $4^{\circ} \mathrm{C}(250 \mathrm{x} \mathrm{g})$. The supernatant was removed. Each sample was combined with $3 \mathrm{~mL}$ of the washing solution (Orpegen Pharma, Heidelberg, Germany) with a temperature of $0^{\circ} \mathrm{C}$. The samples were centrifuged for 5 min at $4^{\circ} \mathrm{C}(250 \mathrm{x}$ $\mathrm{g})$, and the supernatant was removed. A DNA staining solution (Orpegen Pharma, Heidelberg, Germany) chilled to $0^{\circ} \mathrm{C}$ was added in the amount of $200 \mu \mathrm{L}$. The samples were shaken and incubated on ice for 10 min. The phagocytic activity of the evaluated cells was measured in a cytometer (Beckmann Coulter, Epics XL, USA) within less than 60 min after the addition of the last reagent. The Phagotest kit (Orpegen Pharma, Heidelberg, Germany) contains fluorescein (FITC)-stained E. coli bacteria which are phagocytised by macrophages. Cell nuclei are also stained. The number of phagocytising cells, granulocytes and monocytes are determined separately. Phagocytic activity is evaluated based on the mean fluorescence intensity (MFI) of individual cells that ingest bacteria.

Determination of the oxidative metabolism of blood granulocytes and monocytes in calves with the BURSTTEST ${ }^{\circledR}$ Kit

The oxidative metabolism of blood granulocytes and monocytes was determined with the BURSTTEST (Orpegen Pharma, Heidelberg, Germany) based on the attached instructions. The manufacturer's specifications were also observed in the process of preparing the reagents. Whole heparinised blood was split into four portions and placed in four $100 \mu \mathrm{L}$ test tubes (blue, Beckman Coulter, Fullerton, CA, USA) chilled to $0^{\circ} \mathrm{C}$. The first sample (experimental) was combined with $20 \mu \mathrm{L}$ of chilled E. coli bacteria (Orpegen Pharma, Heidelberg, Germany); the second sample (negative control) was combined with $20 \mu \mathrm{L}$ of the washing solution (Orpegen Pharma, Heidelberg, Germany); the third sample (low control) was combined with $20 \mu \mathrm{L}$ of fMLP ( $\mathrm{N}$-formyl-methionyl-leucyl-phenylalanine) (Orpegen Pharma, Heidelberg, Germany); the fourth sample (high control) was combined with $20 \mu \mathrm{L}$ of PMA (4phorbol-12- $\beta$-myristate-13-acetate) (Orpegen Pharma, Heidelberg, Germany). The contents of each test tube were stirred and incubated at $37^{\circ} \mathrm{C}$ for $10 \mathrm{~min}$, excluding the sample containing fMLP which was incubated for 7 min. Twenty $\mu \mathrm{L}$ of substrate solution (Orpegen Pharma, Heidelberg, Germany) was added to each incubated sample, and the tubes were thoroughly shaken. The samples were incubated at $37^{\circ} \mathrm{C}$ for $10 \mathrm{~min}$, and $2 \mathrm{~mL}$ of the lysing solution (Orpegen Pharma, Heidelberg, Germany) at room temperature was added to each test tube. The samples were shaken and incubated at room temperature for 20 min. 
The test tubes were centrifuged at $4^{\circ} \mathrm{C}$ for $5 \min (250 \times \mathrm{g})$, and the supernatant was removed. The samples were rinsed once with $3 \mathrm{ml}$ of the washing solution (Orpegen Pharma, Heidelberg, Germany), they were centrifuged at $4^{\circ} \mathrm{C}$ for $5 \mathrm{~min}(250 \times \mathrm{g})$, and the supernatant was removed. Each sample was combined with $200 \mu \mathrm{L}$ of the staining solution chilled to $0^{\circ} \mathrm{C}$, it was shaken and incubated for $10 \mathrm{~min}$ on ice. The intracellular killing activity of phagocytes was measured in a cytometer (BD Biosciences, San Jose, California, USA) within less than $30 \mathrm{~min}$ after the addition of the last reagent. The cells were stimulated with three activators: E. coli bacteria (Orpegen Pharma, Heidelberg, Germany), PMA (Orpegen Pharma, Heidelberg, Germany) as the strong activator, and fMLP (Orpegen Pharma, Heidelberg, Germany) as the weak activator. Oxidative stress was induced with $\mathrm{H}_{2} \mathrm{O}_{2}$, and mitochondria-generated reactive oxygen species converted dihydrorodamine (123-DHR) to cation rhodamine 123 (R123), the fluorescence emitter.

FACS Acquisition and Analysis

Flow cytometry was performed with the FACSCanto II cytometer (BD Biosciences, San Jose, California, USA). Data were acquired with FACSDiva version 6.1.3 software (BD Biosciences, San Jose, California, USA) and analysed in FlowJo 10 software (Tree Star, Ashland, Oregon, USA). The cytometry setup and tracking beads (CST; BD Biosciences, San Jose, California, USA) were used to initialise the photomultiplier tube (PMT). Unstained control cells and a single stain control for every fluorochrome were prepared and used to establish flow cytometric compensation. Granulocytes and monocytes were gated based on forward and side scatter (FSC/SSC) parameters (Figure 6A).

Granulocytes and counting beads were identified in PerCP to SSC scatter and depicted in FSC to SSC scatter. Data acquisition ended after the acquisition of exactly 2000 events in the region of counting beads. The number of events in the region of granulocytes was counted, and the number of granulocytes in the control sample was compared with the number of granulocytes in the positive control sample after stimulation with fMLP. The decrease in L-selectin expression can be measured simultaneously.

Downregulation of this cell adhesion molecule correlates directly with the activation of neutrophils under exposure to chemotactic factors. Changes in cell shape precede cell migration and can be measured by analysing changes in forward scatter signals during flow cytometry (Figure 6B).

Statistical Analysis

Numerical results were presented as the arithmetic mean \pm SD. The obtained results were processed statistically by two-way ANOVA for orthogonal design. In post-hoc analysis, Dunnett's test was used to compare day 0 with days 15, 30, and 60 in group II (significance of differences between days: (A) $p<0.05$; (B) $p<0.01$; (C) $p<0.001$; (D) $p<0.0001$ ), and Tukey's test for equal groups to compare group II with group I at each time point (significance of differences between groups: ${ }^{\star} p<0.05$; ${ }^{* \star} p<0.01$; ${ }^{\star \star \star} p<$ $0.001 ; \star \star \star \star ~ p<0.0001)$ with the use of GraphPad Prism 7 software. The significance level has been set to $5 \% \mathrm{HMB}$. 


\section{Abbreviations}

BCAA - branched-chain amino acid

BW - body weight

CD - cluster of differentiation

CR3 - complement receptor 3

fMLP - N-formyl-methionyl-leucyl-phenylalanine

GC-SF - granulocyte colony-stimulating factor

HMB - $\beta$-hydroxy- $\beta$-methylbutyrate

HMB-FA - $\beta$-hydroxy- $\beta$-methylbutyrate free acid

HMG-CoA - 3-hydroxy-3-methylglutaryl-coenzyme A

IFN- $\mathbf{Y}$ - interferon- $\boldsymbol{Y}$

IL - interleukin

LEU - leucine

MFI - mean fluorescence intensity

PKA - potential killing activity

PMA - 4-phorbol-12- $\beta$-myristate-13-acetate

SR-A - class A scavenger receptors

TNFR1 - TNF-a receptor 1

TNF- $\mathbf{a}$ - tumour necrosis factor $a$

a-KIC - a-ketoisocaproate

\section{Declarations}

\section{Ethics approval and consent to participate}

Animal experiments were carried out in conformance with the Animal Protection Law (Journal of Laws of 21 February 2005, No. 33, item 289) and upon the recommendations of the Animal Ethics Committee of the University of Warmia and Mazury in Olsztyn. This study was conducted upon the approval of the 
Local Ethics Committee for animal experiments in Olsztyn. Decision No. 18/2013/N. The herd owner gave written informed consent to use the animals in the study.

\section{Consent for publication}

Not applicable

\section{Availability of data and materials}

The datasets used and/or analysed during the current study are available from the corresponding author on reasonable request.

\section{Competing interests}

The authors declare that they have no competing interests.

\section{Funding}

"Project financially co-supported by Minister of Science and Higher Education in the range of the program entitled "Regional Initiative of Excellence" for the years 2019-2022, Project No. 010/RID/2018/19, amount of funding 12.000.000 PLN." (article-processing charges payment).

\section{Authors' contributions}

RW: conceptualization, methodology, software, validation, formal analysis, investigation, resources, data curation, writing-original draft preparation, writing-review and editing, visualization, supervision, project administration, funding acquisition;

JMa: conceptualization, methodology, software, validation, formal analysis, investigation, data curation, writing-original draft preparation, writing-review and editing;

GZ: conceptualization, validation, investigation, resources, writing-review and editing, supervision;

JMi: conceptualization, validation, investigation, writing-review and editing, funding acquisition;

EK-t: investigation, writing-review and editing, visualization;

All authors have read and approved the manuscript.

\section{Acknowledgements}

Not applicable

\section{References}


1. Wójcik R, Milewski S, Małaczewska J, Tański Z, Brzostowski H, Siwicki AK. Defence mechanisms of the offspring of ewes fed a diet supplemented with yeast (Saccharomyces cerevisiae) during pregnancy and lactation. Centr Eur J Immunol 2008;33:197-201.

2. Milewski S, Sobiech P, Bednarek D, Wójcik R, Małaczewska J, Zaleska B, Siwicki AK. Effect of oligosaccharides supplementation on the meat performance traits and selected indicators of humoral immunity in lambs. Bull Vet Inst Pulawy 2010;54:175-9.

3. Wójcik R. Effect of brewer's yeast (Saccharomyces cerevisiae) extract on selected parameters of humoral and cellular immunity in lambs. Bull Vet Inst Pulawy 2010;54:181-7.

4. Ząbek K, Milewski S, Wójcik R, Siwicki AK. Effect of $\beta-1,3 / 1,6-D$-glucan in diet on productivity and humoral and cellular defense mechanisms in sheep. Acta Vet Brno 2013;82:141-6.

5. Wójcik R. The effect of Leiber Beta-S on the selected parameters of immunity in calves. Acta Vet Brno 2014;83:113-8.

6. Godden S. Colostrum management for dairy calves. Vet Clin North Am Food Anim Pract 2008;24:1939.

7. Lora I, Gottardo F, Contiero B, Dall Ava B, Bonfanti L, Stefani A, Barberio A. Association between passive immunity and health status of dairy calves under 30 days of age. Prev Vet Med 2018;152:125.

8. Cooke RF. Effects on animal health and immune function. Vet Clin North Am Food Anim Pract 2019;35:331-41.

9. McGuirk SM. Disease management of dairy calves and heifers. Vet Clin North Am Food Anim Pract 2008;24:139-53.

10. Mee JF. Newborn dairy calf management. Vet Clin North Am Food Anim Pract 2008;24:1-17.

11. Uetake K. Newborn calf welfare: a review focusing on mortality rates. Anim Sci J 2013;84:101-5.

12. Reiten M, Rousing T, Thomsen PT, Otten ND, Forkman B, Houe H, Sørensen JT, Kirchner MK. Mortality, diarrhea and respiratory disease in Danish dairy heifer calves: Effect of production system and season. Prev Vet Med 2018;155:21-6.

13. Windeyer MC, Leslie KE, Godden SM, Hodgins DC, Lissemore KD, LeBlanc SJ. Factors associated with morbidity, mortality, and growth of dairy heifer calves up to 3 months of age. Prev Vet Med 2014;113:231-40.

14. Svensson C, Hultgren J, Oltenacu PA. Morbidity in 3-7-mont-old dairy calves in south-western Sweden, and risk factors for diarrhea and respiratory disease. Prev Vet Med 2006;74:162-79.

15. Roberts GL. Fusobacterial infections: an underestimated threat. Br J Biomed Sci 2000;57:156-62.

16. Garcia M, Shin JH, Schlaefli A, Greco LF, Maunsell FP, Thatcher WW, Santos JE, Staples CR. Increasing intake of essential fatty acids from milk replacer benefits performance, immune responses, and health of preweaned Holstein calves. J Dairy Sci 2015;98:458-77.

17. Hernández-Castellano LE, Özçelik R, Hernandez LL, Bruckmaier RM. Short communication: Supplementation of colostrum and milk with 5-hydroxy-l-tryptophan affects immune factors but not 
growth performance in newborn calves. J Dairy Sci 2018;101:794-800.

18. Flaga J, Korytkowski Ł, Górka P, Kowalski ZM. The effect of docosahexaenoic acid-rich algae supplementation in milk replacer on performance and selected immune system functions in calves. $J$ Dairy Sci 2019;102: 8862-73.

19. Nissen SL, Abumrad NN. Nutritional role of the leucine metabolite $\beta$-hydroxy- $\beta$-methylbutyrate (HMB). J Nutr Biochem 1997;8:1-12.

20. Van Koevering M, Nissen S. Oxidation of leucine and alpha-ketoisocaproate to beta-hydroxy-beta methylbutyrate in vivo. Am J Physiol 1992;262:E27-E31.

21. Szcześniak KA, Ostaszewski P, Fuller JC Jr, Ciecierska A, Sadkowski T. Dietary supplementation of $\beta$ hydroxy- $\beta$-methylbutyrate in animals - a review. J Anim Physiol Anim Nutr (Berl) 2015;99:405-17.

22. Tatara R. Neonatal programming of skeletal development in sheep is mediated by somatotrophic axis function. Exp Physiol 2008;93:763-Q72.

23. Qiao X, Zhang HJ, Wu SG, Yue HY, Zuo JJ, Feng DY, Qi GH. Effect of $\beta$-hydroxy- $\beta$-methylbutyrate calcium on growth, blood parameters, and carcass qualities of broiler chickens. Poult Sci 2013;92:753-9.

24. Vukovich MD, Slater G, Macchi MB, Turner MJ, Fallon K, Boston T, Rathmacher J. Beta-hydroxy-betamethylbutyrate (HMB) kinetics and the influence of glucose ingestion in humans. J Nutr Biochem 2001;12:631-9.

25. Gatnau R, Zimmerman DR, Nissen SL, Wannemuehler M, Ewan RC. Effects of excess dietary leucine and leucine catabolites on growth and immune responses in weanling pigs. J Anim Sci 1995;73:159-65.

26. Krakowski L, Krzyżanowski J, Wrona Z, Kostro K, Siwicki AK. The influence of nonspecific immunostimulation of pregnant sows on the immunological value of colostrums. Vet Immunol Immunopath 2002;87:89-95.

27. Flummer $C$, Theil PK. Effect of $\beta$-hydroxy $\beta$-methyl butyrate supplementation of sows in late gestation and lactation on sow production of colostrum and milk and piglet performance. J Anim Sci 2012;90:372-4.

28. Wójcik R, Małaczewska J, Siwicki AK, Miciński J, Zwierzchowski G. The effect of $\beta$-hydroxy- $\beta$ methylbutyrate (HMB) on the proliferative response of blood lymphocytes and the phagocytic activity of blood monocytes and granulocytes in calves. Pol J Vet Sci 2013;16:567-9.

29. Wójcik R, Małaczewska J, Siwicki AK, Miciński J, Zwierzchowski G. The effect of $\beta$-hydroxy- $\beta$ methylbutyrate (HMB) on selected parameters of humoral immunity in calves. Pol J Vet Sci 2014;17:357-9.

30. Ząbek K, Wójcik R, Milewski S, Małaczewska J, Tański Z, Siwicki AK. Effect of $\beta$-hydroxy- $\beta$ methylbutyrate acid on meat performance traits and selected indicators of humoral immunity in goats. Jpn J Vet Res 2016;64:247-56.

31. Peterson AL, Qureshi MA, Ferket PR, Fuller JC Jr. Enhancement of cellular and humoral immunity in young broilers by the dietary supplementation of beta-hydroxy-beta-methylbutyrate. 
Immunopharmacol Immunotoxicol 1999;21:307-30.

32. Puchajda-Skowrońska H, Siwicki AK, Wójcik R, Pudyszak K. Effects of 3-hydroxy-3-methylbutyrate $(\mathrm{HMB})$ on selected performance indices and non-specific defence mechanisms in geese. Med Weter 2006;62:89-92.

33. Siwicki AK, Fuller JC Jr, Nissen S, Morand M, Pozet F, Vincent F, Kazuń B. Effect of HMB ( $\beta$-hydroxy- $\beta$ methylbutyrate) on in vitro proliferative responses of sheatfish (Silurus glanis) and catfish (Ictalurus melas) lymphocytes stimulated by mitogens. Acta Vet Brno 2004;73:119-22.

34. Siwicki AK, Zakęś Z, Fuller JC Jr, Nissen S, Kazuń K, Głąbski E. The influence of $\beta$-hydroxy- $\beta$ methylbutyrate (HMB) on cell-mediated immunity in tench Tinca tinca (L.): in vitro and in vivo study. Aquacult Int 2006;14:153-61.

35. Ostaszewski P, Kozlowska E, Siwicki AK, Krzyzanowski J, Fuller JC Jr, Nissen S. The immunomodulating activity of dietary ß-hydroxy-ß-methylbutyrate (HMB) in weanling pigs. J Anim Sci 1998;76(Suppl.1):136.

36. Peterson A, Qureshi M, Ferket P, Fuller Jr J. In vitro exposure with $\beta$-hydroxy- $\beta$-methylbutyrate enhances chicken macrophage growth and function. Vet Immunol Immunopathol 1999;67:67-78.

37. Siwicki AK, Fuller JC Jr, Nissen S, Ostaszewski P, Studnicka M. In vitro effects of beta-hydroxy-betamethylbutyrate (HMB) on cell-mediated immunity in fish. Vet Immunol Immunopathol 2000;76:191-7.

38. Siwicki AK, Morand M, Fuller JC Jr, Nissen S, Goryczko K, Ostaszewski P, Kazuń K, Głombski E. Influence of feeding the leucine metabolite $\beta$-hydroxy- $\beta$-methylbutyrate (HMB) on the non-specific cellular and humoral defence mechanisms of rainbow trout (Oncorhynchus mykiss). J Appl Ichthyol 2003;19:44-8.

39. Ostaszewski P, Kostiuk S, Balasinska B, Jank M, Papet I, Glomot F. The leucine metabolite 3-hydroxy3-methylbutyrate (HMB) modifies protein turnover in muscles of laboratory rats and domestic chickens in vitro. J Anim Physiol Anim Nutr 2000;84:1-8.

40. Slater G, Jenkins D, Logan P, Lee H, Vukovich M, Rathmacher JA, Hahn AG. Beta-hydroxy-betamethylbutyrate (HMB) supplementation does not affect changes in strength or body composition during resistance training in trained men. Int J Sport Nutr Exerc Metab 2001;11:384-96.

41. Ransone J, Neighbors K, Lefavi R, Chromiak J. The effect of beta-hydroxy beta-methylbutyrate on muscular strength and body composition in collegiate football players. J Strength Cond Res 2003;17:34-39.

42. Thomson JS, Watson PE, Rowlands DS. Effects of nine weeks of beta-hydroxy-beta-methylbutyrate supplementation on strength and body composition in resistance trained men. J Strength Cond Res 2009;23:827-35.

43. Wilkinson DJ, Hossain T, Hill DS, Phillips BE, Crossland H, Williams J, Loughna P, Churchward-Venne TA, Breen L, Phillips SM, Etheridge T, Rathmacher JA, Smith K, Szewczyk NJ, Atherton PJ. Effects of leucine and its metabolite beta-hydroxy-beta-methylbutyrate on human skeletal muscle protein metabolism. J Physiol 2013;591:2911-23. 
44. Wójcik R, Małaczewska J, KaczorekŁukowska E. The applicability of the Migratest@ kit for evaluating the chemotactic activity of peripheral blood neutrophils in goats on the example of animals supplemented with $\beta$-hydroxy- $\beta$-methylbutyrate (HMB). Pol. J. Vet. Sci. 2019;22:725-733. doi.org/10.5601/jelem.2019.24.4.1529.

45. Wójcik R, Ząbek K, Małaczewska J, Milewski S, Kaczorekłukowska E. The effects of $\beta$-hydroxy- $\beta$ methylbutyrate (HMB) on chemotaxis, phagocytosis, and oxidative burst of peripheral blood granulocytes and monocytes in goats. Animals 2019;9:1031.

46. Siwicki AK, Głąbski E, Kazuń K, Kazuń B, Lepa A, Majewicz-Zbikowska M. Effect of dietary administration of the $\beta$-hydroxy- $\beta$-methylbutyrate on the innate immunity and protection against motile Aeromonas septicaemia in fish. Centr Eur J Immunol 2011;36:135-38.

47. Guilhem A, Malcus C, Clarivet B, Plauchu H, Dupuis-Girod S. Immunological abnormalities associated with hereditary haemorrhagic telangiectasia. J Intern Med 2013;274:351-62.

\section{Figures}



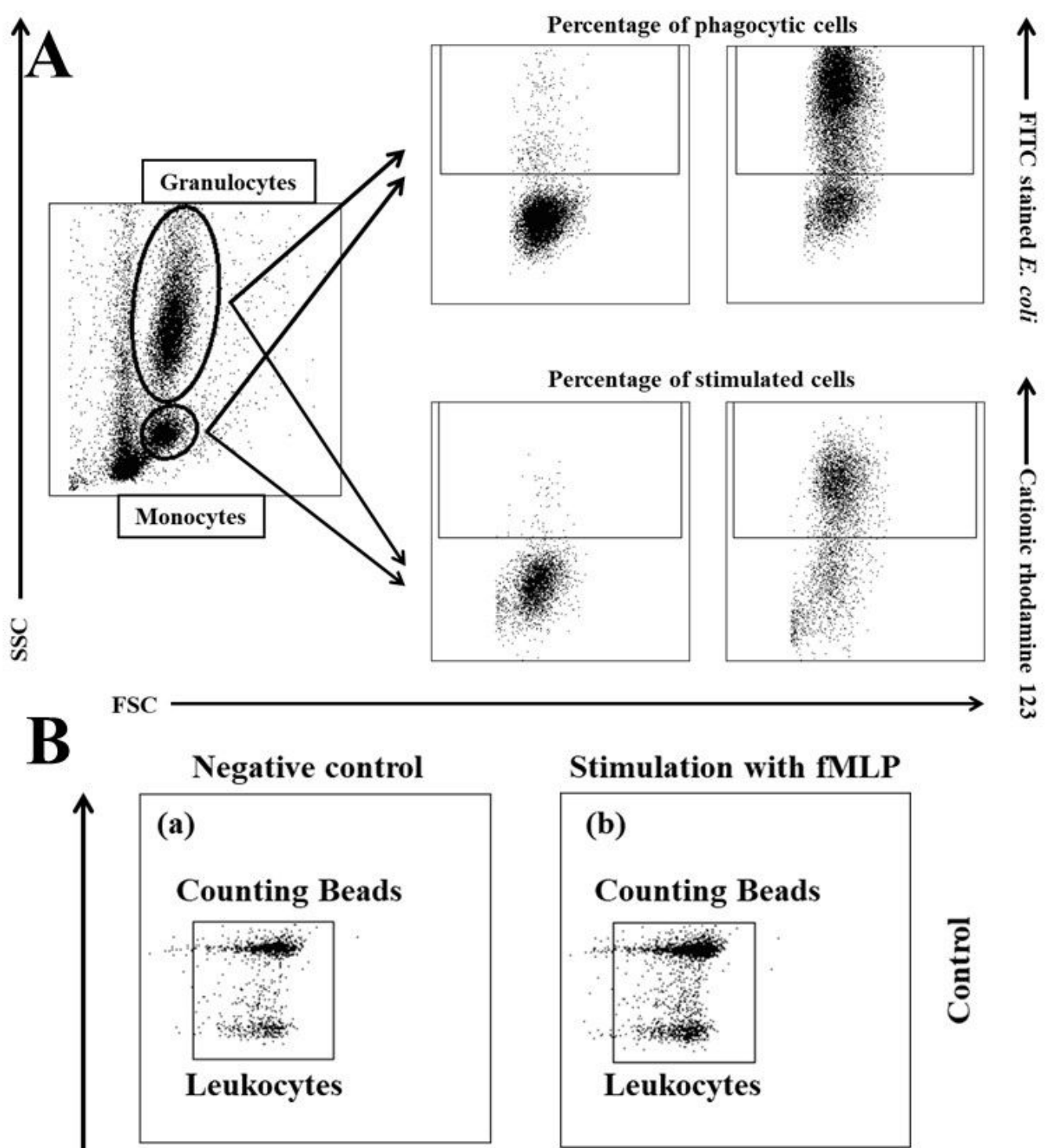

Stimulation with fMLP

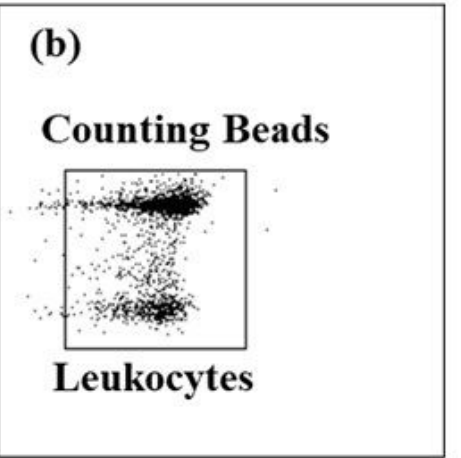

نํ.

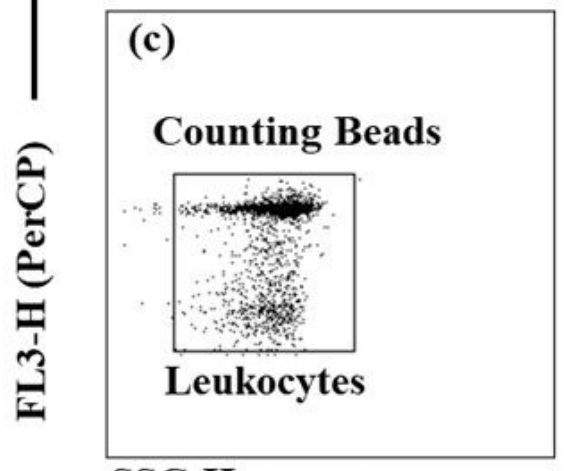

(d)

Counting Beads

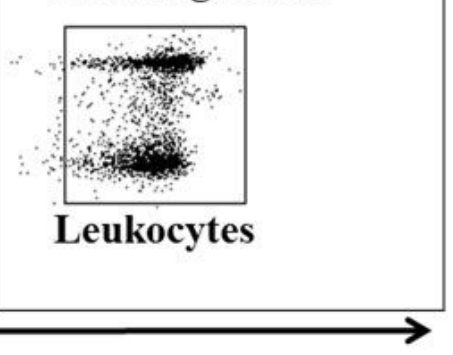

象

\section{Figure 1}

A. The chemotactic index was calculated by dividing the number of cells that migrated towards fMLP by the number of cells that migrated in the absence of fMLP. Key: I - control group; II - experimental group; SD - standard deviation; Numerical results were presented as the arithmetic mean \pm SD. The significance level was set at 0.05 . Asterisks refer to statistically significant differences between control and experimental group within the same sampling day at $* * p<0.01 ; * \star * p<0.001 ;$ C refer to statistically 
significant differences between day "0" and the consecutive sampling days within experimental group at $C-p<0.001$. B. Representative dot plot cytograms showing the percentage of migrating granulocytes and counting beads on day 30 of the experiment. (a) - control without stimulation; (b) - control stimulated with fMLP; (c) - HMB without stimulation; (d) - HMB stimulated with fMLP. The number of granulocytes relative to the number of whole cells was determined in each sample as soon as 2000 counting beads were acquired. Stimulation with $\mathrm{fMLP}$ increased the number of migrated granulocytes (b), (d) relative to the controls without fMLP (a), (c).

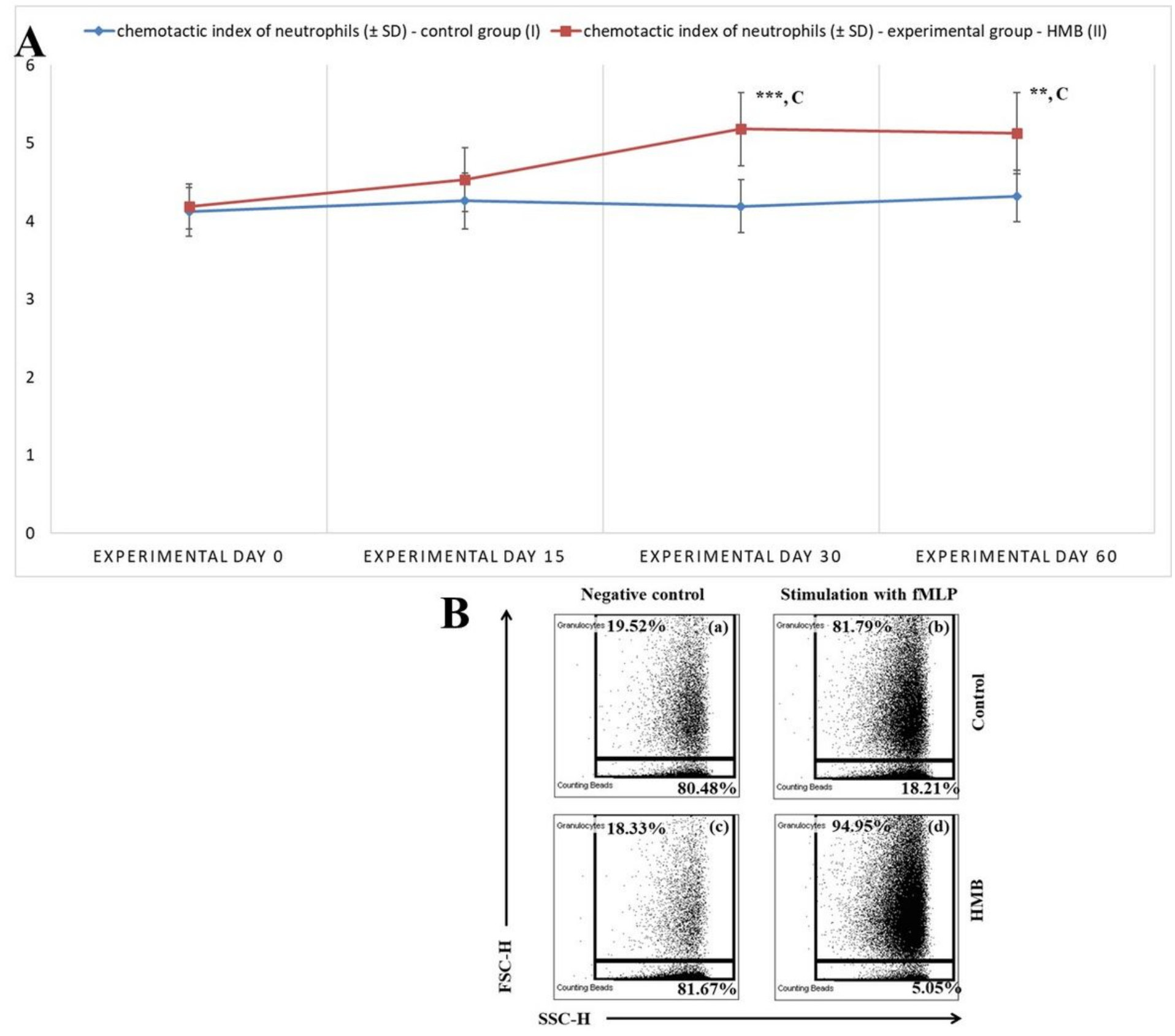

Figure 2

A. Percentage of phagocytising granulocytes in calf groups, as determined in the Phagotest ${ }^{\circledR}$ kit. Key: I control group; II - experimental group; SD - standard deviation. Numerical results were presented as the arithmetic mean \pm SD. The significance level was set at 0.05 . Asterisks refer to statistically significant 
differences between control and experimental group within the same sampling day at * $p<0.05$; $* \star p<$ 0.01; A refer to statistically significant differences between day " 0 " and the consecutive sampling days within experimental group at $A-p<0.05$. B. Dot plot cytogram showing the percentage of phagocytising granulocytes in control and experimental calves on experimental day 30 . Whole heparinised blood from control and experimental animals was incubated for 10 minutes with FITC-labelled E. coli in an ice bath at a temperature of $0^{\circ} \mathrm{C}$ (negative control) or in a water bath at a temperature of $37^{\circ} \mathrm{C}$ (control and $\mathrm{HMB}$ ). The percentages of granulocytes with ingested $\mathrm{E}$. coli (FITC) bacteria were gated. C. Mean fluorescence intensity (MFI) of granulocytes in calf groups, as determined in the Phagotest ${ }^{\circledR}$ kit. Key: I - control group; II - experimental group; SD - standard deviation; Numerical results were presented as the arithmetic mean \pm SD. The significance level was set at 0.05 . Asterisks refer to statistically significant differences between

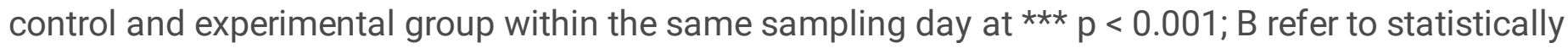
significant differences between day " 0 " and the consecutive sampling days within experimental group at $B-p<0.01$.
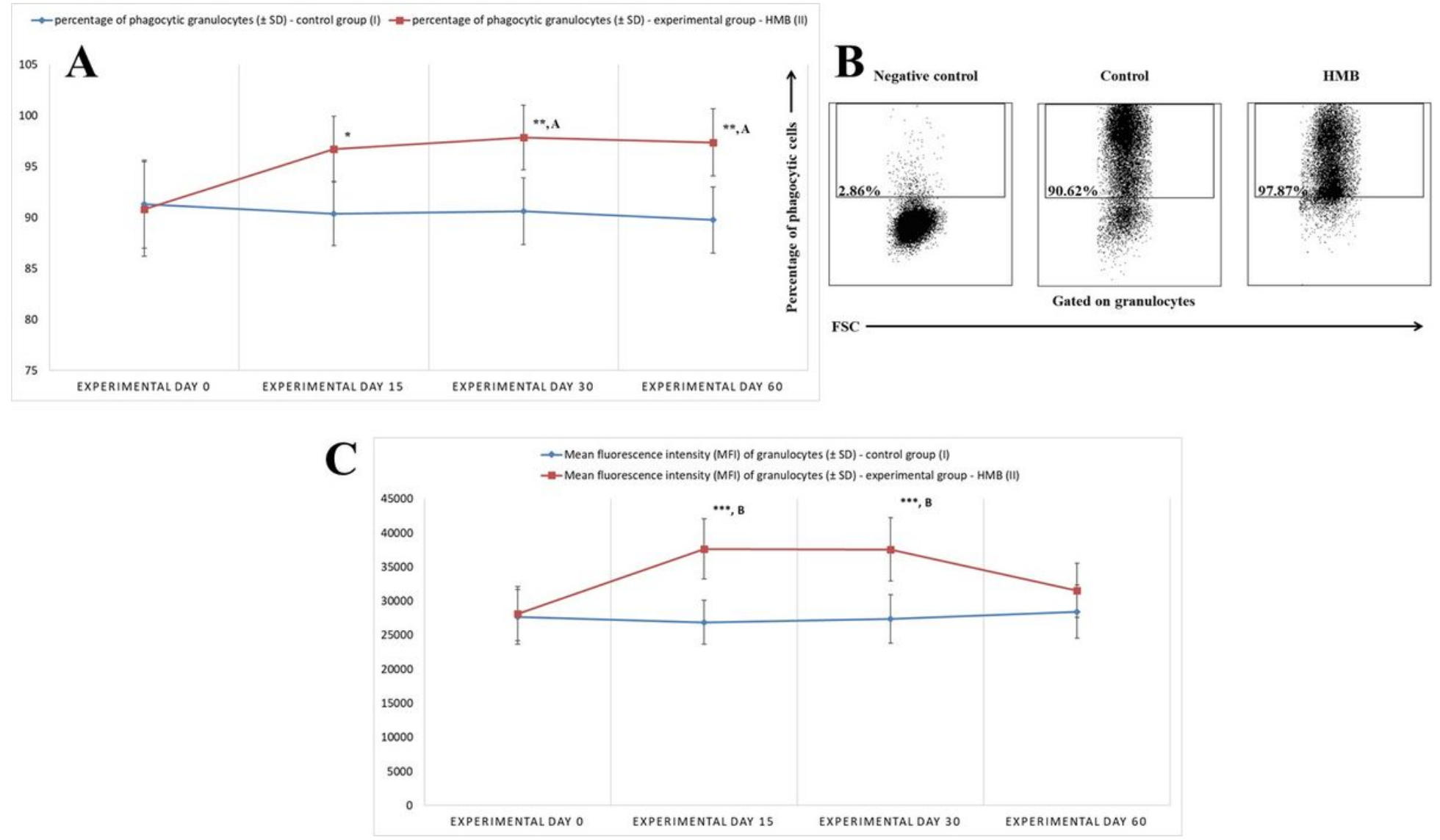

\section{Figure 3}

A. Percentage of phagocytising monocytes in calf groups, as determined in the Phagotest ${ }^{\circledR}$ kit. Key: I control group; II - experimental group; SD - standard deviation. Numerical results were presented as the arithmetic mean $\pm S D$. The significance level was set at 0.05 . Asterisks refer to statistically significant differences between control and experimental group within the same sampling day at $* \star \star p<0.001$; $* \star \star \star p$ $<0.0001$; D refer to statistically significant differences between day " 0 " and the consecutive sampling days within experimental group at $D-p<0.0001$. B. Dot plot cytogram showing the percentage of 
phagocytising monocytes in control and experimental calves on experimental day 30 . Whole heparinised blood from control and experimental animals was incubated for 10 minutes with FITC-labelled E. coli in an ice bath at the temperature of $0^{\circ} \mathrm{C}$ (negative control) or in a water bath at the temperature of $37^{\circ} \mathrm{C}$ (control and HMB). The percentages of monocytes with ingested $\mathrm{E}$. coli (FITC) bacteria were gated. C. Mean fluorescence intensity (MFI) of monocytes in calf groups, as determined in the Phagotest ${ }^{\circledR}$ kit. Key: I - control group; II - experimental group; SD - standard deviation. Numerical results were presented as the arithmetic mean $\pm S D$. The significance level was set at 0.05 . Asterisks refer to statistically significant differences between control and experimental group within the same sampling day at ${ }^{\star \star \star} p<0.001 ; * \star \star \star p$ $<0.0001$; D refer to statistically significant differences between day "0" and the consecutive sampling days within experimental group at $D-p<0.0001$.
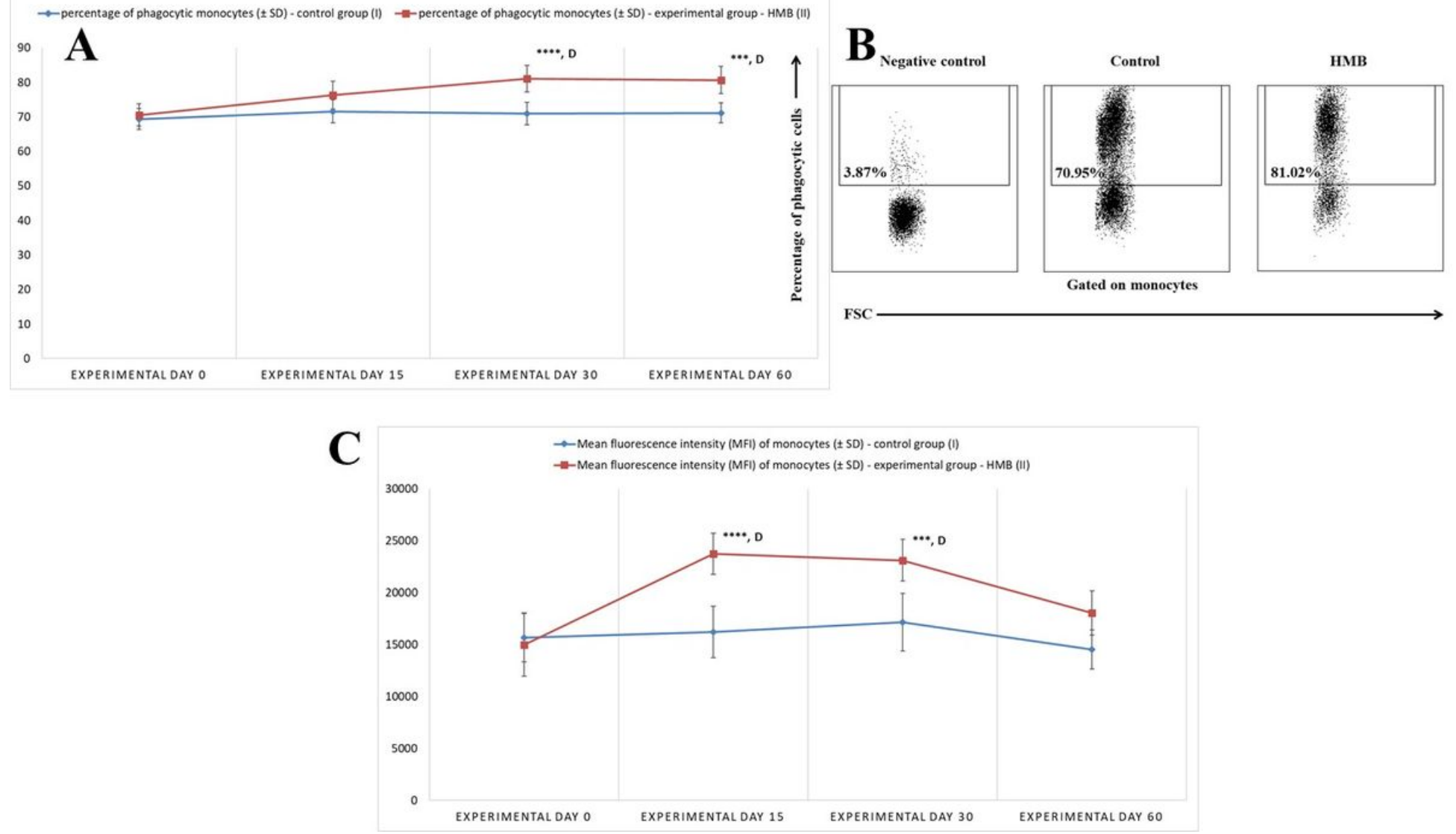

\section{Figure 4}

A. Percentage of granulocytes stimulated to undergo respiratory burst in calf groups after stimulation with $\mathrm{fMLP}, \mathrm{PMA}$ and E. coli, as determined in the Bursttest ${ }^{\circledR}$ kit. Key: I - control group; II - experimental group; SD - standard deviation. Numerical results were presented as the arithmetic mean \pm SD. The significance level was set at 0.05 . Asterisks refer to statistically significant differences between control and experimental group within the same sampling day at * $p<0.05$; ** $p<0.01 ; A, B$ refer to statistically significant differences between day " 0 " and the consecutive sampling days within experimental group at $A-p<0.05 ; B-p<0.01$. B. Dot plot cytogram showing the percentage of granulocytes stimulated to undergo respiratory burst in control and experimental calves on experimental day 30 . Whole heparinised blood from control and experimental animals (control and HMB) was divided into four test tubes. The 
samples were combined with the washing solution (negative control), E. coli bacteria (opsonising activator), PMA (strong activator) or fMLP (weak activator) and incubated with dihydrorhodamine 123 in a water bath at a temperature of $37^{\circ} \mathrm{C}$. After incubation, cells were lysed and DNA staining solution was added. The percentages of granulocytes stimulated to undergo respiratory burst (conversion of dihydrorhodamine 123 to rhodamine 123) were gated. C. Mean fluorescence intensity (MFI) of granulocytes in calf groups after stimulation with fMLP, PMA and E. coli, as determined in the Bursttest ${ }^{\circledR}$ kit. Key: I - control group; II - experimental group; SD - standard deviation. Numerical results were presented as the arithmetic mean \pm SD. The significance level was set at 0.05 . Asterisks refer to statistically significant differences between control and experimental group within the same sampling day at ${ }^{*} p<0.05 ; * \star p<0.01 ; * \star * p<0.001 ; * \star \star * ~ p<0.0001 ; B, C, D$ refer to statistically significant differences between day "0" and the consecutive sampling days within experimental group at $\mathrm{B}-\mathrm{p}<$ $0.01 ; C-p<0.001 ; D-p<0.0001$.
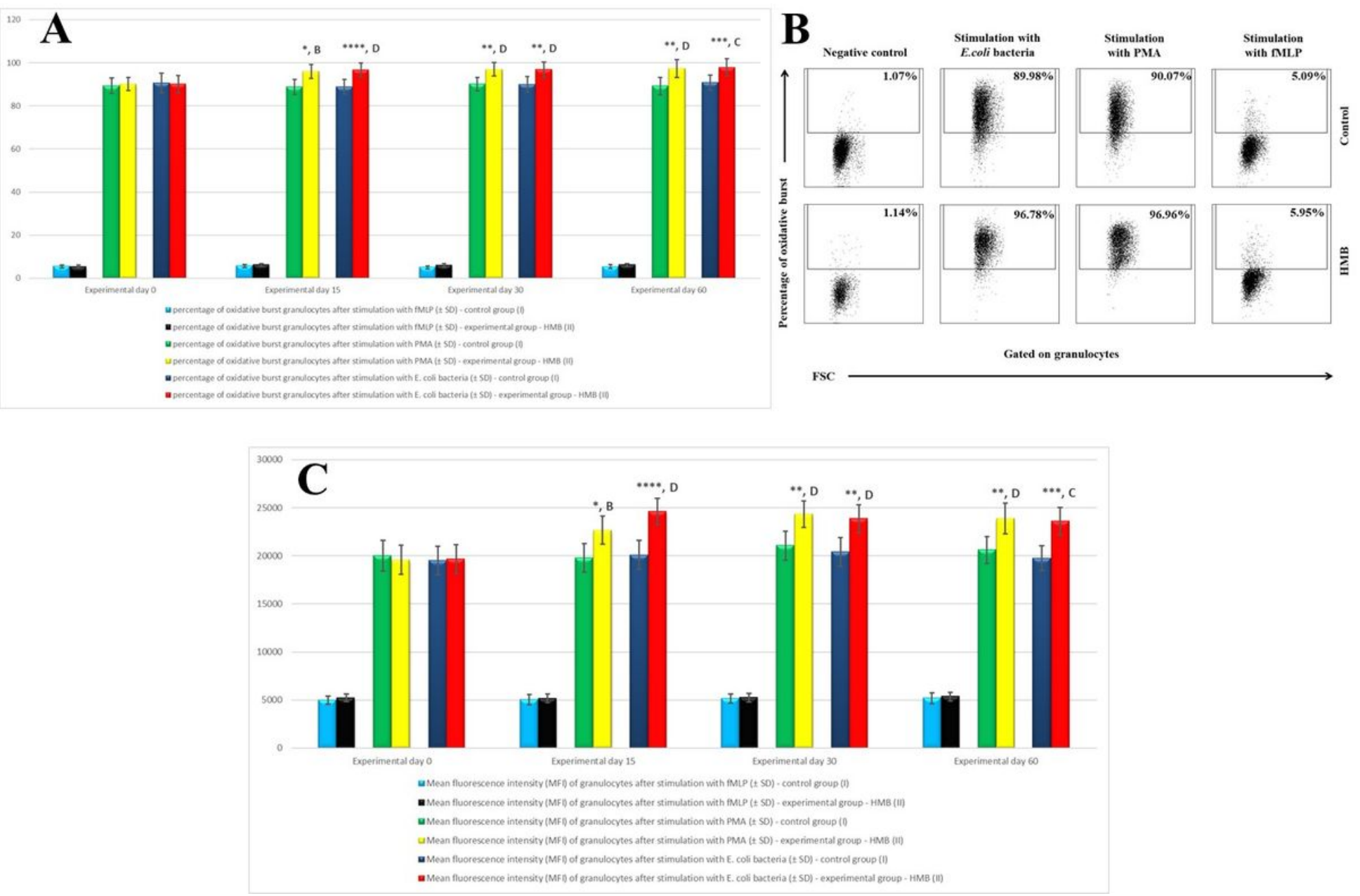

\section{Figure 5}

A. The percentage of monocytes stimulated to undergo respiratory burst in calf groups after stimulation with $\mathrm{fMLP}, \mathrm{PMA}$ and E. coli, as determined in the Bursttest ${ }^{\circledR}$ kit. Key: I - control group; II - experimental group; SD - standard deviation. Numerical results were presented as the arithmetic mean \pm SD. The significance level was set at 0.05 . Asterisks refer to statistically significant differences between control 
and experimental group within the same sampling day at $* p<0.05 ;{ }^{* \star} p<0.01 ; * \star \star p<0.001 ; B, C$ refer to statistically significant differences between day "0" and the consecutive sampling days within experimental group at $B-p<0.01 ; C-p<0.001$. B. Dot plot cytogram showing the percentage of monocytes stimulated to undergo respiratory burst in control and experimental animals on experimental day 30. The percentages of monocytes stimulated to undergo respiratory burst were gated. C. Mean fluorescence intensity (MFI) of monocytes in calf groups after stimulation with $\mathrm{FMLP}$, PMA and E. coli, as determined in the Bursttest ${ }^{\circledR}$ kit. Key: I - control group; II - experimental group; SD - standard deviation; Numerical results were presented as the arithmetic mean \pm SD. The significance level was set at 0.05 . Asterisks refer to statistically significant differences between control and experimental group within the same sampling day at * $p<0.05 ; * \star p<0.01 ; A, B, C$ refer to statistically significant differences between day " 0 " and the consecutive sampling days within experimental group at $A-p<0.05 ; B-p<0.01 ; C-p$ $<0.001$.
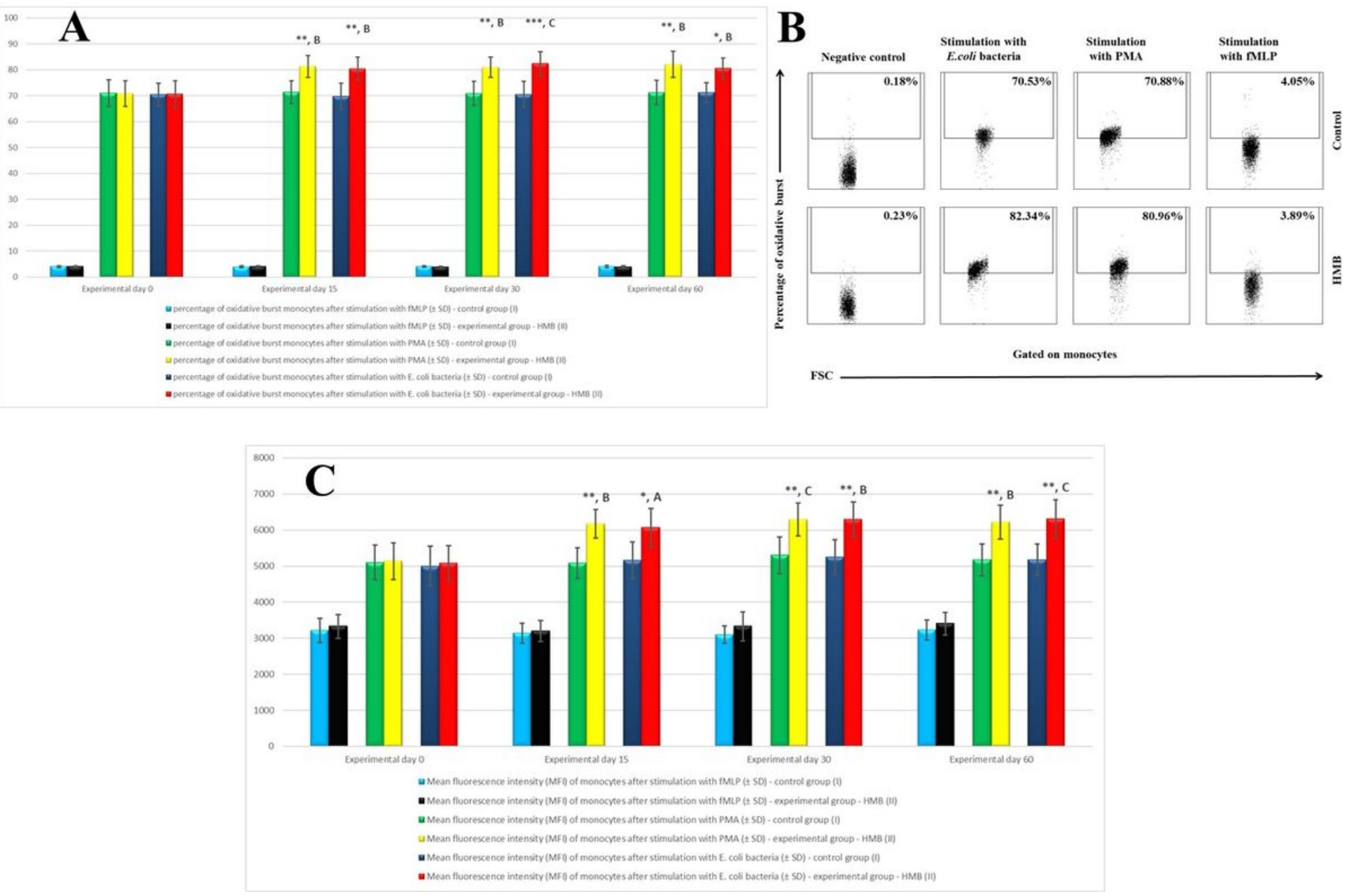

\section{Figure 6}

A. Gating strategy for flow cytometry data analysis. Granulocytes and monocytes were gated based on forward and side scatter (FSC/SSC) parameters. Each cell subset was analysed for the relative number of phagocytising cells and cells stimulated for respiratory burst (fMLP, PMA or E. coli bacteria). B. Gating strategy for analysing flow cytometry data based on the neutrophil migration assay. Granulocytes and 
counting beads were identified in PerCP to SSC scatter and depicted in FSC to SSC scatter. (a) - control without stimulation; (b) - control stimulated with fMLP; (c) - HMB without stimulation; (d) - HMB stimulated with $\mathrm{fMLP}$.

\section{Supplementary Files}

This is a list of supplementary files associated with this preprint. Click to download.

- NC3RsARRIVEGuidelinesChecklistfillable.pdf 